\title{
Catalysis by Organic Solids. Stereoselective Diels-Alder Reactions Promoted by Microporous Molecular Crystals Having an Extensive Hydrogen-Bonded Network
}

\author{
Ken Endo, ${ }^{\dagger}$ Takashi Koike, ${ }^{\dagger}$ Tomoya Sawaki, ${ }^{\dagger}$ Osamu Hayashida, ${ }^{\dagger}$, \\ Hideki Masuda, ${ }^{\S, *}$ and Yasuhiro Aoyama ${ }^{*, \dagger, *}$
}

\begin{abstract}
Contribution from the Institute for Fundamental Research of Organic Chemistry, Kyushu University, Hakozaki, Higashi-Ku, Fukuoka 812-81, Japan, CREST, Japan Science and Technology Corporation (JST), and Department of Applied Chemistry, Nagoya Institute of Technology, Gokiso-Cho, Showa-Ku, Nagoya 466, Japan
\end{abstract}

Received December 5, $1996^{\otimes}$

\begin{abstract}
Anthracenebisresorcinol derivative 1 as an organic network material shows a novel catalysis in the solid state for the acrolein-cyclohexadiene Diels-Alder reaction. The suggested mechanism involves a catalytic cycle composed of sorption of the reactants in the cavities of polycrystalline host $\mathbf{1}$, preorganized intracavity reaction, and desorption of the product. The host also promotes stereoselective intracavity reactions for alkyl acrylates and cyclohexadiene but, in this case, not in a catalytic manner. Relevance of the present system as a functional organic analog of zeolites is discussed in light of the kinetics of respective elementary processes and the effects of pulverization of the catalyst thereupon as well as X-ray crystal structures.
\end{abstract}

\section{Introduction}

Solid-state reactions constitute an important area of selective organic reactions. ${ }^{1}$ There are also many examples of lattice inclusion compounds, ${ }^{2}$ in which the host affects the rates and stereochemistry of the reactions of included guest molecules. ${ }^{1}$ To the best of our knowledge, however, organic solids have seldom been used as catalysts. ${ }^{3}$ In fact, solid or heterogeneous catalysts including zeolites ${ }^{4}$ have so far been exclusively inorganic materials. We are particularly interested in the construction of organic network materials as functional analogs of zeolites. ${ }^{5}$ Organic molecules show a remarkable diversity not only in molecular structures but also in network dimensionalities and topologies. ${ }^{6}$ The cavity sizes ${ }^{7}$ and functional catalytic groups are also designable in principle.

We have recently shown that anthracenebisresorcinol derivative 1 (Scheme 1) forms a hydrogen-bonded network whose cavities are capable of crystalline-phase guest-addition, -removal, and -exchange. ${ }^{8}$ Interestingly, small polar and apolar guest

$\dagger$ Kyushu University.

$¥$ CREST

$\S$ Nagoya Institute for Technology.

$\otimes$ Abstract published in Advance ACS Abstracts, April 1, 1997.

(1) (a) Schmidt, G. M. J. Pure Appl. Chem. 1971, 27, 647-678. (b) Green, B. S.; Lahav, M.; Rabinovioch, D. Acc. Chem. Res. 1979, 12, 191197. (c) Addadi, L.; Ariel, S.; Lahav, M.; Leiserowitz, L.; Popovitz-Biro, R.; Tang, C. P. Chem. Phys. Solids Their Surf. 1980, 8, 202-244. (d) Scheffer, J. R. Acc. Chem. Res. 1980, 13, 283-290. (e) Desiraju, G. R., Ed.; Organic Solid State Chemistry; Elsevier: Amsterdam, 1987. (f) Ramamurthy, V.; Venkatesan, K. Chem. Rev. 1987, 87, 433-481. (g) Toda, F.; Top. Curr. Chem. 1988, 149, 211-238. (h) Toda, F. Synlett 1993, 303312. (i) Toda, F. Acc. Chem. Res. 1995, 28, 480-486.

(2) For a list of recent publications on lattice inclusion compounds, see: Aoyama, Y.; Endo, K.; Kobayashi, K.; Masuda, H. Supramolec. Chem. 1995, 4, 229-241.

(3) For recent publications very briefly referring to apparently catalytic behaviors of organic crystals, see: (a) Toda, F.; Tanaka, K.; Sekikawa, A. J. Chem. Soc., Chem. Commun. 1987, 279-280. (b) Soai, K.; Watanabe, M. Ibid. 1990, 43-44. (c) Fujita, M.; Kwon, Y. J.; Washuzu, S.; Ogura, K. Ibid. 1994, 116, 1151-1152.

(4) (a) Hölderich, W.; Hesse, M.; Näumann, F. Angew. Chem., Int. Ed. Engl. 1988, 27, 226-246. (b) Suib, S. L. Chem. Rev. 1993, 93, 803-826. (c) Breck, D. W. Zeolite Molecular Sieves, Structure, Chemistry, and Use; John Wiley \& Sons: New York, 1974.
Scheme 1

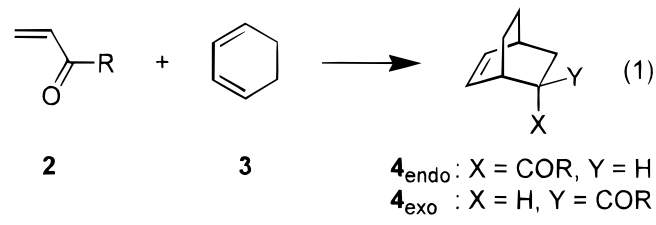

$\mathrm{a}: \mathrm{R}=\mathrm{H}$

$b: \mathrm{R}=\mathrm{OCH}_{2} \mathrm{CH}_{3}$

$c: \mathrm{R}=\mathrm{O}\left(\mathrm{CH}_{2}\right)_{3} \mathrm{CH}_{3}$

$\mathrm{d}: \mathrm{R}=\mathrm{OCH}_{2} \mathrm{CH}\left(\mathrm{CH}_{3}\right)_{2}$

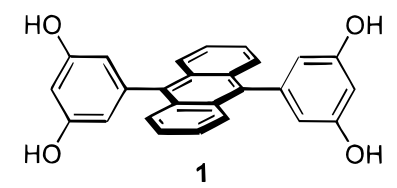

molecules can be bound simultaneously in the cavity as in adduct $\mathbf{1} \cdot 2\left(\mathrm{CH}_{3} \mathrm{CO}_{2} \mathrm{CH}_{2} \mathrm{CH}_{3}\right) \cdot 2\left(\mathrm{C}_{6} \mathrm{H}_{6}\right){ }^{9}{ }^{9}$ The present work is concerned with Diels-Alder reactions (eq 1 in Scheme 1) between enclathrated acrolein $(\mathbf{2 a})$ or an acrylic ester $(\mathbf{2} \mathbf{b}-\mathbf{d})$

(5) For selected examples, see: (a) Barrer, R. M.; Shanson, V. H. J. Chem. Soc., Chem. Commun. 1976, 333-334. (b) Ermer, O. J. Am. Chem. Soc. 1988, 110, 3747-3754. (c) Weber, E.; Pollex, R.; Czugler, M. J. Org. Chem. 1992, 57, 4068-4070. (d) Copp, S. B.; Subramanian, S.; Zaworotko, M. J. Ibid. 1992, 114, 8719-8720. (e) Reddy, D. S.; Craig, D. C.; Rae, A. D.; Desiraju, G. R. J. Chem. Soc., Chem. Commun. 1993, 1737-1739. (f) Wang, X.; Simard, M.; Wuest, J. D. J. Am. Chem. Soc. 1994, 116, 1211912120. (g) Venkataraman, D.; Lee, S.; Zhang, J.; Moore, J. S. Nature 1994, 371, 591-593. (h) Reddy, D. S.; Craig, D. C.; Desiraju, G. R. J. Am. Chem. Soc. 1996, 118, 4090-4093.

(6) (a) For a list of recent publications on the formation of ordered crystal structures involving hydrogen-bonded 1D, 2D, and 3D motifs, see: Aoyama, Y.; Endo, K.; Anzai, T.; Yamaguchi, Y.; Sawaki, T.; Kobayashi, K.; Kanehisa, N.; Hashimoto, H.; Kai, Y.; Masuda, H. J. Am. Chem. Soc. 1996 118, 5562-5571. Also see: (b) MacDonald, J. C.; Whitesides, G. M. Chem. Rev. 1994, 94, 2383-2420. (c) Valiyaveettil, S.; Enkelmann, V.; Mülln, K. J. Chem. Soc., Chem. Commun. 1994, 2097-2098. (d) Hosseini, M. W.; Ruppert, R.; Schaeffer, P.; De Cian, A.; Kyritsakas, N.; Fischer, J. Ibid. 1994, 2135-2136. For examples of (infinite) metal-coodination networks, see: (e) Abrahams, B. F.; Hoskins, B. F.; Liu, J.; Robson, R. J. Am. Chem. Soc. 1991, 113, 3045-3051. (f) Reference 3c. (g) Reference 5d. (h) Stang, P. J.; Cao, D. H.; Saito, S.; Arif, A. M. Ibid. 1995, 117, 6273-6283. (i) Fujita, M.; Kwon, Y. J.; Sasaki, O.; Yamaguchi, K.; Ogura, K. Ibid. 1995, 117, 7287-7288.

(7) Cf., Endo, K.; Ezuhara, T.; Koyanagi, M.; Masuda, H.; Aoyama, Y. J. Am. Chem. Soc. 1997, 119, 499-505. 


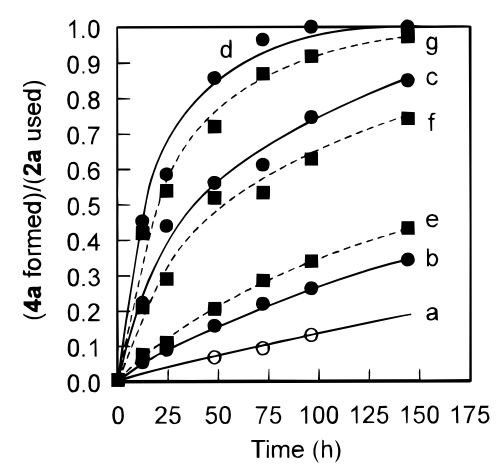

Figure 1. Time courses of the reactions of dienophile $2 \mathrm{a}(1.5 \mathrm{mmol})$ and diene $\mathbf{3}(30 \mathrm{mmol})(\mathbf{2} \mathbf{a} / \mathbf{3}=20)$ at $25^{\circ} \mathrm{C}$ in the presence and absence of host $\mathbf{1}$ as either nonpulverized pieces (runs $\mathrm{b}-\mathrm{d}$ ) or pulverized powders (runs e $-\mathrm{g}$ ): 1/2a $=0$ (a), $0.017(\mathrm{~b}$ and e), $0.033(\mathrm{f}), 0.083(\mathrm{c}$ and g), 0.17 (d).

as a dienophile and 1,3-cyclohexadiene (3) in place of ethyl acetate and benzene, respectively. We report here that host 1 promotes highly stereoselective intracavity reactions either catalytically for aldehyde dienophile $\mathbf{2 a}$ or stoichiometrically for ester dienophiles $\mathbf{2 b}-\mathbf{d} .^{10-12}$

\section{Results and Discussion}

Catalytic Acrolein-Diene and Stoichiometric AcrylateDiene Reactions. The liquid-phase reaction of acrolein (2a) and cyclohexadiene (3) (eq 1 of Scheme 1) is very slow at 25 ${ }^{\circ} \mathrm{C}$ but is accelerated by host $\mathbf{1}$ in the solid state, giving rise to a 95:5 mixture of the endo and exo products $\mathbf{4} \mathbf{a}_{\text {endo }}$ and $\mathbf{4} \mathbf{a}_{\text {exo }}$. Figure 1 shows the time courses of the reactions in the absence (a) and presence $(b-g)$ of a catalytic amount $(\mathbf{1} / \mathbf{2 a}=0.017(\mathrm{~b}$ and e), 0.033 (f), 0.083 (c and g), 0.17 (d)) of the host as either nonpulverized pieces (approximate size, $1 \times 1 \times 1 \mathrm{~mm}^{3}$ ) (runs $\mathrm{b}-\mathrm{d}$ shown in solid lines) or pulverized powders (runs $\mathrm{e}-\mathrm{g}$ shown in dashed lines) sitting in a 1:20 mixture of dienophile 2a and diene 3. Host $\mathbf{1}$ is hardly soluble in the present 3-rich solution. Nevertheless, the reactions are faster in the presence of increasing amounts of the host. There is in fact a linear dependence of the rate constants ${ }^{13}$ of the reactions and the amounts of nonpulverized (solid line) or pulverized (dashed line) host as shown in Figure 2, where the amounts of product 4a formed and host $\mathbf{1}$ used are normalized with that of limiting

(8) (a) Reference 2. (b) Endo, K.; Sawaki, T.; Koyanagi, M.; Kobayashi, K.; Masuda, H.; Aoyama, Y. J. Am. Chem. Soc. 1995, 117, 8341-8352. (c) Reference $6 \mathrm{a}$.

(9) Kobayashi, K.; Endo, K.; Aoyama, Y.; Masuda, H. Tetrahedron Lett. 1993, 34, 7929-2932.

(10) Diels-Alder reactions have been demonstrated to occur in the solid state by cocrystallization of diene and dienophile: Kishan, K. V. R.; Desiraju, G. R. J. Org. Chem. 1987, 52, 4641-4644. Also see: Sergeev, G. B.; Komarov, V. S.; Zvonov, A. V. Dokl. Akad. Nauk SSSR 1983, 270, 139-142.

(11) For Diels-Alder reactions in the host-guest systems, see: (a) Walter, C. J.; Anderson, H. L.; Sanders, J. K. M. J. Chem. Soc., Chem. Commun. 1993, 458-460 (high exo-selectivity). (b) Hirst, S. C.; Hamilton, A. D. J. Am. Chem. Soc. 1991, 113, 382-383 (intramolecular reaction). (c) Sternbach, D. D.; Rossana, D. M. Ibid. 1982, 104, 5853-5854 (intramolecular reaction). (d) Rideout, D. C.; Breslow, R. Ibid. 1980, 102, 7816-7817 (hydrophobic acceleration). For other pericyclic reactions, see; (e) Mock, W. C.; Irra, T. A.; Wepsiec, J. P.; Adhya, M. J. Org. Chem. 1989, 54, 5302-5308. (f) Ueno, A.; Moriwaki, F.; Iwama, Y.; Suzuki, I.; Osa, T.; Ohta, T.; Nozoe, S. J. Am. Chem. Soc. 1991, 113, 7034-7036.

(12) Solid-state photodimerization of olefins is well-known and is also relevant to the present reactions (reference 1). Also see: Granagura, K.; Ramasubbu, N.; Verkatesan, K.; Ramamurthy, V. J. Org. Chem. 1985, 50, 2337-2346.

(13) The slope of the yield-time plots (Figure 1) at an early stage of the reaction corresponds to the pseudo-first-order rate constant, the accurate value of which can also be obtained by the standard pseudo-first-order treatment of the kinetic data.

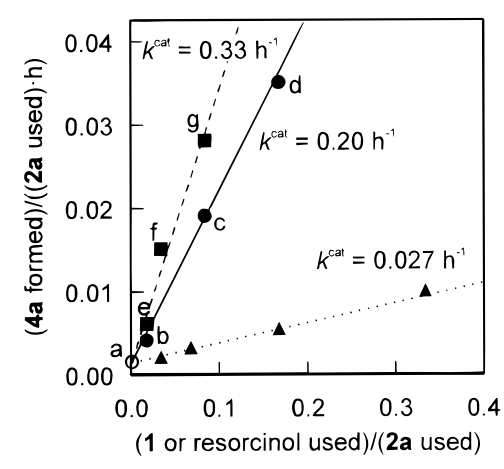

Figure 2. Correlations between rate constants and normalized amounts of catalysts: nonpulverized host $\mathbf{1}$ in the solid state (solid line), pulverized host $\mathbf{1}$ in the solid state (dashed line), and soluble resorcinol (dotted line). Runs $\mathrm{a}-\mathrm{g}$ refer to those in Figure 1.

substrate 2a used. Clearly, the facilitated reactions go beyond the amounts of the host up to the completion. These results indicate that host $\mathbf{1}$ functions as a catalyst with a turnover rate constant of $k^{\text {cat }}=0.20 \mathrm{~h}^{-1}$ for nonpulverized host or $0.33 \mathrm{~h}^{-1}$ for pulverized host; it is obtained as the slope, (mole of $\mathbf{4 a}$ formed $) /(($ mole of $\mathbf{1}$ used $) h)$, of the linear correlation between rate constants and amounts of host 1 (Figure 2).

It is easy to demonstrate that the catalysis is exerted by the solid host. The solubility of host 1 in the present 1:20 mixture of $\mathbf{2 a}$ and $\mathbf{3}$ is unmeasurably small. If the solubilized host, if any, were the catalyst, runs $b-g$ (Figure 1) having the same concentration of the host at saturation should have the same rates. This is not the case. The rates of the reactions show a linear dependence on the amounts of insoluble host. It is also confirmed that a supernatant solution separated from insoluble host $\mathbf{1}$ by filtration exhibits practically the same rate as the reference run (run a). The catalytic activity of solubilized host can be evaluated by using a $\mathbf{2 a}$-rich solution, e.g., a 10:1 mixture of $\mathbf{2 a}$ and $\mathbf{3}$, in which host $\mathbf{1}$ is significantly soluble. Treatment, in a similar manner as above (Figures 1 and 2), of the kinetic data with respect to limiting substrate $\mathbf{3}$ in the absence and presence of varying amounts of the host reveals that $k^{\mathrm{cat}}=$ $0.02 \mathrm{~h}^{-1}$ as the slope of a linear correlation between rate constants, (4a formed)/((3 used $) h)$, and (1 used $) /(\mathbf{3}$ used $) .{ }^{14}$ Thus, the homogeneous catalysis $\left(k^{\mathrm{cat}}=0.02 \mathrm{~h}^{-1}\right)$ by the solubilized host is less pronounced as compared with heterogeneous catalysis $\left(k^{\text {cat }}=0.20\right.$ or $\left.0.33 \mathrm{~h}^{-1}\right)$ by the same host in the solid state. Evaluation of the homogeneous catalytic activity of resorcinol in the 1:20 (2a to $\mathbf{3})$ mixture leads to a similar conclusion: $k^{\text {cat }}=0.027 \mathrm{~h}^{-1}$ (dotted line in Figure 2). ${ }^{14}$ Furthermore, it is important to note that resorcinol shows practically no catalysis in the solid state, ${ }^{15}$ in marked contrast to host 1. Another interesting observation is that the present reaction is subject to inhibition by an otherwise inert compound such as methyl benzoate (vide infra).

To our surprise, change in dienophiles from acrolein (2a) to ethyl acrylate $(\mathbf{2 b})$ results in a dramatic change in the overall features. Host $\mathbf{1}$, which turns out to be a catalyst in the acrolein system, shows almost no catalysis in the acrylate-diene reaction.

Sorption of Reactants. Recrystallization at room temperature of the host from a mixture of acrolein (2a) and cyclo-

(14) This treatment of homogeneous kinetic data is only for the purpose of comparison with heterogeneous kinetic data; it is difficult to define concentration for an insoluble catalyst.

(15) Resorcinol is soluble in the present reaction mixture $(\mathbf{2 a} / \mathbf{3}=1: 20)$ up to the amount of resorcinol/2a $=0.33$, where the pseudo-first-order rate constant of the reaction is $\sim 0.01 \mathrm{~h}^{-1}$ (Figure 2). Further addition of resorcinol results in its precipitation without causing any notable increase in the rate. 


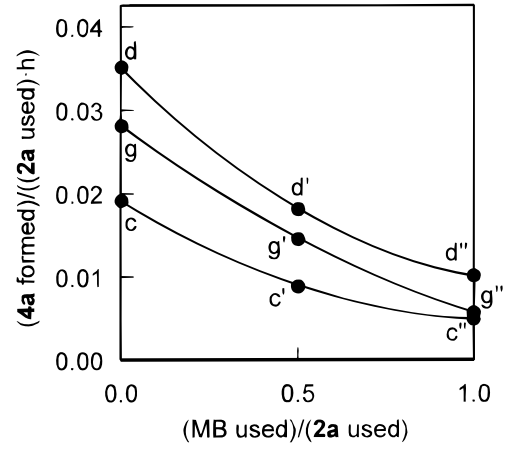

Figure 3. Correlations between rate constants and normalized amounts of methyl benzoate (MB) as an inhibitor under otherwise identical conditions for runs $\mathrm{c}, \mathrm{d}$, and $\mathrm{g}$.

hexadiene (3) affords a quaternary adduct $\mathbf{1} \cdot x(\mathbf{2 a}) \cdot x(\mathbf{3}) \cdot y(\mathbf{4 a})$ containing Diels-Alder product $\mathbf{4 a}$ in addition to both of the reactants. The composition ( $x$ and $y)$ changes $(2>x>0$ and $0<y<2)$ with duration of recrystallization, while keeping $(x$ $+y)=2$; the total $1 /$ dienophile/diene ratio is maintained at $1: 2: 2$. Recrystallization even at $-23{ }^{\circ} \mathrm{C}$ fails to give single crystals of adduct $\mathbf{1} \cdot 2(\mathbf{2 a}) \cdot 2(\mathbf{3})$ completely free from product 4a. The crystal structure of a similar 1:2:2 adduct $\mathbf{1} \cdot 2\left(\mathrm{CH}_{3}-\right.$ $\left.\mathrm{CO}_{2} \mathrm{CH}_{2} \mathrm{CH}_{3}\right) \cdot 2\left(\mathrm{C}_{6} \mathrm{H}_{6}\right)$ has been determined. ${ }^{9}$ The two ester molecules are hydrogen-bonded to the host in each cavity, and the two benzene molecules occupy the void space left, resulting in a close ester-benzene proximity.

Crude adduct $\mathbf{1} \cdot 2(\mathbf{2 a}) \cdot 2(\mathbf{3})$ can be also obtained by dipping the host in a relatively $\mathbf{2 a - r i c h}$ solution, e.g., a 1:1 mixture of 2a and 3, although the resulting adduct subsequently dissolves in the solution. This is why we are forced to carry out the catalytic reactions by using a highly hydrocarbon-rich solution. Actually, when dipped in a 1:20 (2a to 3) mixture, host 1 rapidly (in seconds to minutes) forms an adduct of an apparent composition of $\mathbf{1} \cdot \mathbf{2} \mathbf{a} \cdot 3(\mathbf{3})$. As the reaction proceeds, product 4a accumulates in the cavity; the composition of the adduct at $60 \%$ conversion of the catalytic reaction is $\mathbf{2} \mathbf{a} / \mathbf{3} / \mathbf{4} \mathbf{a} \cong 1: 1: 2$.

These results strongly suggest that the internal cavities of host 1 provide the sites of reaction. This is further supported by the competitive inhibition of the reactions by methyl benzoate (MB), which is a potential guest of the present host. ${ }^{8 a, b}$ Figures I, II, and III (Supporting Information) show the time courses of the reactions in the absence and presence of $\mathrm{MB}$ at an inhibitor/ reactant ratio of $\mathrm{MB} / \mathbf{2 a}=0.5$ or 1 under otherwise identical conditions for runs $\mathrm{c}, \mathrm{d}$, and g. Figure 3 shows how the rate constants (c, d, and g) decrease with increasing amounts of soluble MB; inhibition is $\sim 50 \%\left(\mathrm{c}^{\prime}, \mathrm{d}^{\prime}\right.$, and $\left.\mathrm{g}^{\prime}\right)$ or $70-80 \%$ $\left(c^{\prime \prime}, d^{\prime \prime}\right.$, and $\left.g^{\prime \prime}\right)$ at $\mathrm{MB} / \mathbf{2 a}=0.5$ or 1 , respectively. Independent measurements indicate that host 1 preferentially binds inhibitor $\mathrm{MB}$ rather than reactant $\mathbf{2} \mathbf{a}$ in a ratio of $\mathrm{MB} / \mathbf{2} \mathbf{a}=3$ or 8 when the composition in the solution phase is $\mathrm{MB} / \mathbf{2} \mathbf{a}=0.5$ or 1 , respectively.

When ethyl acrylate (2b) is used in place of acrolein (2a), host $\mathbf{1}$ affords a $1: 2: 1$ adduct $\mathbf{1} \cdot 2(\mathbf{2 b}) \cdot \mathbf{3}$ upon recrystallization or solid-state complexation. ${ }^{16}$ The acrylate adduct is kinetically more stable than the acrolein adduct. The former retains singlecrystallinity at low temperatures to allow X-ray diffraction studies at $230 \mathrm{~K}$. The crystal structure ${ }^{17}$ is summarized as follows in reference to Figure 4, where anthracene rings,

(16) Recrystallization of host $\mathbf{1}$ from a mixture of ethyl acrylate (2b) and benzene affords a similar $1: 2: 1$ adduct $\mathbf{1} \cdot 2(\mathbf{2 b}) \cdot\left(\mathrm{C}_{6} \mathrm{H}_{6}\right)$.

(17) $P 2_{1} / n, a=23.804(6) \AA, b=13.814(4) \AA, c=24.314(3) \AA, \beta=$ $109.34(1)^{\circ}, V=7544.1 \AA^{3}, Z=4, d_{\text {calcd }}=1.19 \mathrm{~g} / \mathrm{cm}^{3}$, number of unique reflections $=9728\left(2 \theta \leq 51.4^{\circ}\right)$, number of reflections used $=4600\left(I_{0}<\right.$ $\left.3 \sigma\left(I_{0}\right)\right), R=0.062$, and $R_{\mathrm{W}}=0.070$. resorcinol rings, dienophile $\mathbf{2 b}$, and diene $\mathbf{3}$ are shown in red, black, green, and pink, respectively, and hydrogen bonds are in light blue. (1) Host $\mathbf{1}$ forms a hydrogen-bonded $(\mathrm{O}-\mathrm{H} \cdots \mathrm{O}-$ $\mathrm{H})$ network to give a $2 \mathrm{D}$ sheet (Figure 4a), where neighboring anthracene columns $\mathrm{c}$ and $\mathrm{c}^{\prime}$ are not equivalent in respect to the orientation of included guest molecules. (2) In contrast to those in related adducts, ${ }^{6 a, 8,9}$ two neighboring anthracene rings along a column are not parallel so that the cavities roofed and bottomed there are not cylindrical but bowl-shaped, as shown by a side view (Figure $4 \mathrm{~b}$ and its explanation $4 \mathrm{c}$ ) of two adjacent cavities in column c. Two dienophile (2b) molecules, being roughly parallel with nearby anthracene rings, are bound in each cavity via host - guest hydrogen-bonding $(\mathrm{O}-\mathrm{H} \cdots \mathrm{O}-\mathrm{H} \cdots \mathrm{O}=\mathrm{C})$ with their vinyl $(\mathrm{C}=\mathrm{C})$ groups pointing to the wider or open side. (3) Diene 3 occupies the space left in this side in such a way as to be sandwiched by the vinyl groups of the ester guests (side views of Figure 4b,c and top view (d) with its explanation (e) where front (top) and rear (bottom) molecules of $\mathbf{2} \mathbf{b}$ are shown in thick and thin lines, respectively). (4) The guestbinding mode in the cavities in column $\mathrm{c}^{\prime}$ is similar but the orientation of dienophile $\mathbf{2 b}$ is opposite; the ethoxy groups instead of the vinyl point to the open side and sandwich diene 3 (illustrations $c^{\prime}$ and $\mathrm{e}^{\prime}$, where double bonds of cyclohexadiene can not be fixed because of disorder).

Intracavity Reactions. Good evidence for the intracavity Diels-Alder reactions comes from solid-gas experiments, where host $\mathbf{1}$ is allowed to be in contact with the vapors of the guests at $25{ }^{\circ} \mathrm{C}$ in a sealed vessel. ${ }^{8}$ The initially formed hostdienophile-diene ternary adducts of an approximate composition of $\mathbf{1} \cdot 2(\mathbf{2 a}) \cdot 2(\mathbf{3})$ or $\mathbf{1} \cdot 2(\mathbf{2 b}) \cdot \mathbf{3}$ are ultimately converted to the corresponding product adducts $\mathbf{1} \cdot 2(\mathbf{4 a})$ and $\mathbf{1} \cdot \mathbf{2 b} \cdot \mathbf{4} \mathbf{b}$. The reactant adducts obtained by recrystallization or solid-liquid complexation behave similarly. Thus, the crystalline-phase intracavity reactions are complete on the stoichiometric basis, leaving $1 \mathrm{~mol}$ of excess dienophile $\mathbf{2 b}$ intact for the acrylate adduct.

The stereoisomer ratios for the intracavity reactions increase with increasing steric bulkiness of the substituents $(\mathrm{R})$ in dienophiles $\mathrm{H}_{2} \mathrm{C}=\mathrm{CH}(\mathrm{C}=\mathrm{O}) \mathrm{R} ; \mathbf{4}_{\text {endo }} / \mathbf{4}_{\text {exo }}=95: 5,98: 2$, 99:1, and $(>99)$ : $(<1)$ when $\mathrm{R}=\mathrm{H}(\mathrm{a}), \mathrm{OCH}_{2} \mathrm{CH}_{3}(\mathrm{~b}), \mathrm{O}\left(\mathrm{CH}_{2}\right)_{3} \mathrm{CH}_{3}$ (c), and $\mathrm{OCH}_{2} \mathrm{CH}\left(\mathrm{CH}_{3}\right)_{2}$, respectively. For comparison, the selectivities of reference runs in the absence of host $\mathbf{1}$ at reflux temperatures are $\mathbf{4}_{\text {endo }} / \mathbf{4}_{\text {exo }} \cong 87: 13$ and slightly higher ( $\left.\sim 9: 1\right)$ at $25{ }^{\circ} \mathrm{C}$ and are practically independent of substituents $(\mathrm{R})$. The crystal structure for the reactant adduct $\mathbf{1} \cdot 2(\mathbf{2 b}) \cdot \mathbf{3}$ is not very suggestive of the stereoselectivity. Almost nothing is known about the actual reaction geometry in cavity $\mathrm{c}^{\prime}$. In cavity c, an ene-diene proximity $(\sim 3.8 \AA$; Figure $4 \mathrm{~b})$ is assured but their orientation is not suited for reaction (Figure $4 \mathrm{e}$ ). Rotation of diene 3 by either $60^{\circ}$ or $120^{\circ}$ brings the diene moiety into an orientation suitable for reaction with the dienophile, expectedly giving rise to the endo $\left(\mathbf{4} b_{\text {endo }}\right)$ or the exo $\left(\mathbf{4} b_{\text {exo }}\right)$ product, respectively.

Because of technical problems, ${ }^{18}$ it is difficult to follow the kinetics of intracavity reactions accurately. Only an approximate half-life of $\tau=2 \mathrm{~h}$ (corresponding to the first-order rate constant of $k_{1}{ }^{\text {cav }}=0.3 \mathrm{~h}^{-1}$ ) can be estimated for the acrolein-diene (2a$\mathbf{3})$ reaction. The acrylate-diene $(\mathbf{2} \mathbf{b}-\mathbf{3})$ reaction, which takes longer, turns out to be biphasic. The relatively slow reaction with $\tau=20 \mathrm{~h}\left(k_{1}{ }^{\text {cav }}=0.03 \mathrm{~h}^{-1}\right)$ up to $\sim 50 \%$ conversion is followed by a much faster reaction in the second stage. The biphasic nature may be understood on the basis of the crystal

(18) One of the problems, especially for the acrolein system, is spontaneous desorption of included cyclohexadiene from the isolated adducts. Thus, the adducts undergoing intracavity reactions should be kept under the vapor of the diene. 

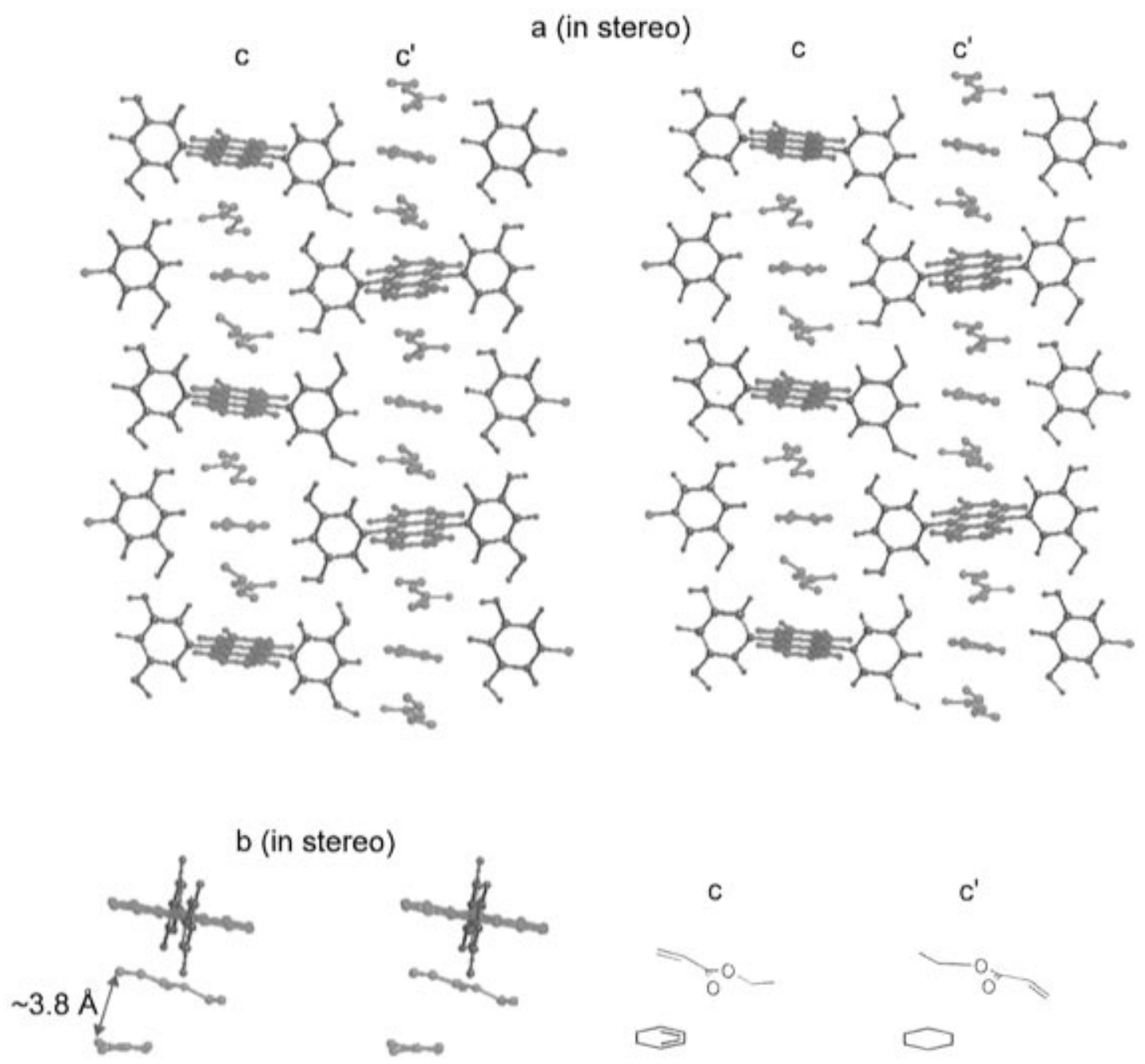

b (in stereo)
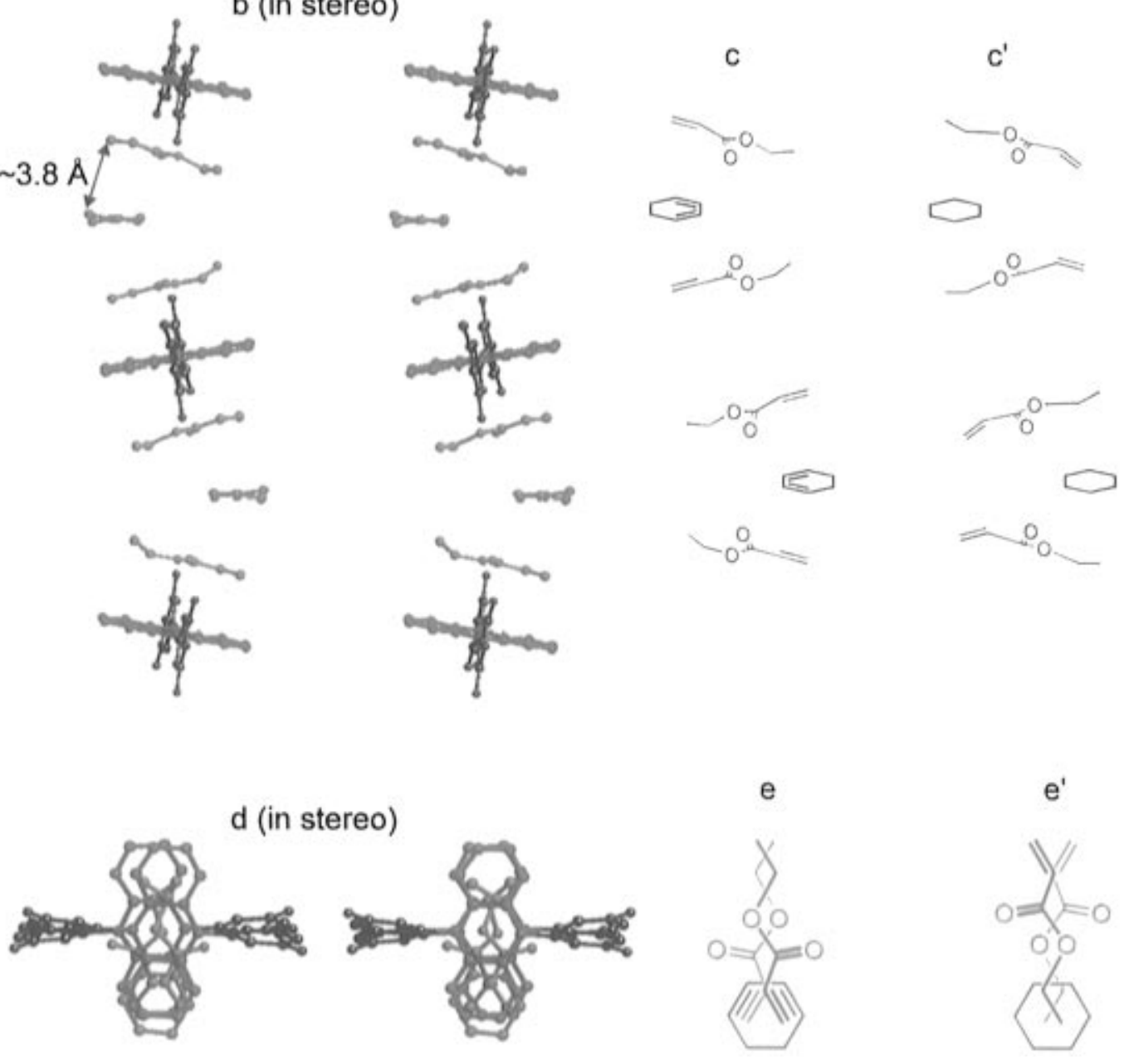

Figure 4. Crystal structure of adduct $\mathbf{1} \cdot 2(\mathbf{2 b}) \cdot \mathbf{3}$ at $230 \mathrm{~K}$; two neighboring columns $\mathrm{c}$ and $\mathrm{c}^{\prime}$ in a $2 \mathrm{D}$ sheet constructed by a hydrogen-bonded network (a), side view of two adjacent cavities of column c (b) and its explanation (c), top view of a cavity of column c (d) and its explanation (e), and guest-binding mode (in schematic form) in cavities of column $\mathrm{c}^{\prime}$ ( $\mathrm{c}^{\prime}$ and $\mathrm{e}^{\prime}$ where double bonds of cyclohexadiene can not be fixed because of disorder). The anthracene rings, resorcinol rings, dienophile $\mathbf{2 b}$, and diene $\mathbf{3}$ are shown in red, black, green, and pink, respectively, and hydrogen bonds are represented in light blue. 
structure. There are two types of the cavities, i.e., those along columns $\mathrm{c}$ and $\mathrm{c}^{\prime}$. The former (cavity $\mathrm{c}$ ) is reactive, since diene $\mathbf{3}$ is sandwiched by the vinyl groups of dienophile $\mathbf{2 b}$ (Figure 4). In the latter (cavity $c^{\prime}$ ), it is the ethoxy groups of the dienophile that sits above and below the six-membered ring of the diene (Figure $4 c^{\prime}, e^{\prime}$ ). A drastic change in the crystal structure might take place when the reaction in cavity $\mathrm{c}$ is complete.

The approximate kinetic parameters estimated above are not very dependent on whether the starting adducts are pulverized or not. They may be compared with the pseudo-first-order rate constants of $k_{1}^{\text {uncat }}=1.3 \times 10^{-3} \mathrm{~h}^{-1}(\tau=500 \mathrm{~h})$ and $\leq 2 \times$ $10^{-4} \mathrm{~h}^{-1}(\tau \geq 3000 \mathrm{~h})$, respectively, for $\mathbf{2 a}$ and $\mathbf{2 b}$, in the uncatalyzed liquid-phase $\mathbf{2 a}-\mathbf{3}$ and $\mathbf{2 b}-\mathbf{3}$ reference reactions under pseudo-first-order conditions, i.e., for the 1:20 dienophilediene mixtures (cf. run a in Figure 1). There is little doubt that the facilitation of the intracavity reactions is primarily due to the proximity of dienophile and diene simultaneously bound in a cavity.

The proximity effects ${ }^{19}$ are often expressed in terms of effective concentration factors $(m)$ by using the equation $k_{1}{ }^{\text {cav }}$ $=k_{2} m$, where $k_{1}{ }^{\text {cav }}$ is the observed first-order rate constant in respect to one reactant, e.g., dienophile in the present case, of a preorganized bimolecular reaction, $m$ is the effective molarity of the reaction partner, i.e., diene, and $k_{2}$ is the second-order rate constant for the reference reaction in homogeneous solution. Putting experimental values of $k_{1}{ }^{\text {cav }}=0.3 \mathrm{~h}^{-1}$ and $k_{2}=1.3 \times$ $10^{-4} \mathrm{M}^{-1} \mathrm{~h}^{-1}$ and $k_{1}{ }^{\text {cav }}=0.03 \mathrm{~h}^{-1}$ and $k_{2} \leq 2 \times 10^{-5} \mathrm{M}^{-1} \mathrm{~h}^{-1}$ for the acrolein-diene and acrylate-diene reactions, ${ }^{20}$ the effective molarities of the enclathrated cyclohexadiene can be calculated as $m=2000$ and $\geq 1500 \mathrm{M}$ for the acrolein and acrylate systems, respectively. For comparison, 1,3-cyclohexadiene as a neat liquid has a molarity of $\sim 10 \mathrm{M}$. Thus, geometrical factors play a decisive role. The proximity effects, however, may not be the sole origin of rate enhancement. Diels-Alder reactions are well-known to be accelerated by acids, especially Lewis acids, which activate enone-type dienophiles via coordination. ${ }^{21}$ A slight but distinct catalysis by soluble resorcinol is noted above. The fixed hydrogen-bonding between host and dienophile may provide a potential source of acid catalysis in the present intracavity reactions..$^{22,23}$

Desorption of Products. It is in the fate of intracavity Diels-Alder products that the acrolein and the acrylate systems differ essentially. When the acrolein product adduct $\mathbf{1} \cdot 2(\mathbf{4 a})$ in powders is dipped in a 1:20 (2a to $\mathbf{3}$ ) mixture, product $\mathbf{4 a}$ included can be exchanged with reactants $2 \mathbf{a}$ and $\mathbf{3}$. This process is biphasic. About $50 \%$ of $\mathbf{4 a}$ bound is rapidly exchanged in seconds to minutes, while desorption of the remaining 50\% takes hours. The adduct in nonpulverized pieces exhibits a similar overall feature. ${ }^{24}$ In marked contrast, the acrylate-diene product $\mathbf{4 b}$ resists to be exchanged by its

(19) Storm, D. R.; Koshland, D. E., Jr. J. Am. Chem. Soc. 1972, 94, 5805-5814.

(20) $k_{2}=k_{1}$ uncat/[3], where [3] $\cong 10 \mathrm{M}$ for the 1:20 mixture of dienophile $\mathbf{2 a}$ or $\mathbf{2 b}$ and diene $\mathbf{3}$.

(21) (a) Kagan, B. F.; Riant, O. Chem. Rev. 1992, 92, 1007-1019. (b) Pindur, U.; Luiz, G.; Otto, C. Ibid. 1993, 93, 741-761.

(22) There is no doubt that acrolein incorporated is hydrogen-bonded to the host, as evidenced by a large $\left(30 \mathrm{~cm}^{-1}\right)$ shift to lower wavenumber in $v_{\mathrm{C}=\mathrm{O}}$ for acrolein upon adduct formation.

(23) There are numerous examples of facilitated solid-state reactions via hydrogen bonding (reference 1). For the effect of hydrogen bonding on the tautomeric composition, see: Herbstein, F. H.; Kapon, M.; Reisner, G. M.; Lehman, M. S.; Kress, R. B.; Wilson, R. B.; Shiau, W. I.; Duesler, E. N.; Paul, I. C.; Curtin, D. Y. Proc. R. Soc. London 1985, A399, 295-319.

(24) The size-insensitivity of the desorption properties might be interpreted as suggesting that the biphasic nature is due to some kind of phase transition in the crystal structure upon guest desorption or exchange and not due to its dependence on the depth of the cavity from the surface. components when product adduct $\mathbf{1} \cdot \mathbf{4 b} \cdot \mathbf{2} \mathbf{b}$ is dipped in a 1:20 (2b to 3 ) mixture. The different behaviors of the two adducts is not due to the difference in incoming dienophiles $\mathbf{2 a}$ vs $\mathbf{2 b}$. When dipped in a solution of methyl acrylate (MA) and diene

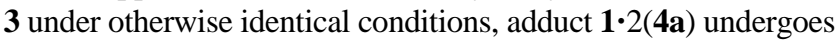
facile $\mathbf{4 a} /(\mathrm{MA}+\mathbf{3})$ exchange, while adduct $\mathbf{1} \cdot \mathbf{4 b} \cdot \mathbf{2 b}$ shows practically no tendency of $4 \mathrm{~b} /(\mathrm{MB}+3)$ exchange.

Guest-exchange may be controlled by both steric and electronic factors. The acrolein product $\mathbf{4 a}$ as an aldehyde is less bulky and less basic than the acrylate product $\mathbf{4 b}$ as an ester; basicity may be an important factor that governs hostguest hydrogen-bonding. It might be easier for smaller guests less strongly hydrogen-bonded to the host to leave the cavity and diffuse in the solid. At the present, however, knowledge is too scarce to allow a convincing explanation for the remarkable difference in the desorption abilities of the acrolein and acrylate products $\mathbf{4 a}$ and $\mathbf{4 b}$. We have to learn more about the general mechanism of lattice diffusion. ${ }^{25}$ Another decisive factor is how host-guest hydrogen-bonding changes, in geometry and strength, upon reaction.

Catalytic Mechanism. Combination of the elementary processes leads to a simplified catalytic mechanism of the acrolein-cyclohexadiene reaction. It involves (a) initial binding of reactants (in seconds to minutes), (b) intracavity reaction (in hours), and (c) product/reactant exchange (biphasic; in seconds to minutes and hours for the faster and slower phases, respectively). The relative time scales of respective steps suggest that step b must be rate-determining, in accord with the kinetics of catalytic reactions. ${ }^{26}$ Step c can also be partially rate-limiting; catalyst $\mathbf{1}$ indeed exists as quarternary adducts incorporating both product and reactants in the course of the catalysis (vide supra). It is also evident that host $\mathbf{1}$ fails to catalyze the acrylate-diene $(\mathbf{2} \mathbf{b}-\mathbf{3})$ reaction due to product inhibition.

The surface often plays important or essential roles in heterogeneous catalyses, where catalytic activities usually show dramatic size-dependencies. The biphasic nature of step c above may suggest a depth-dependence of the catalytic abilities of internal cavities. ${ }^{24}$ It is also possible that only cavities near the surface actually take part in the catalytic processes. The point, however, is that there is no evidence to believe that the present catalysis is simply a surface phenomenon. (1) The elementary processes show no essential dependence on whether the host or its adduct is pulverized or not. The effect of pulverization on the overall catalytic (turnover) rate constants is only by a factor of $1.7\left(k^{\text {cat }}=0.20\right.$ and $0.33 \mathrm{~h}^{-1}$ for nonpulverized and pulverized host, respectively; Figure 2). Thus, the size effect is quite modest at best. (2) The surface mechanism seems to fail to give a good explanation why acrylate product $\mathbf{4 b}$, and not the acrolein product $4 \mathbf{a}$, formed on the surface should continue to stay there to deactivate the catalytic sites. The stereoselectivity $\left(\mathbf{4} \mathbf{a}_{\text {endo }} / \mathbf{4} \mathbf{a}_{\text {exo }}=95: 5\right)$ of the catalytic acrolein-diene reaction is the same as that of the single-turnover

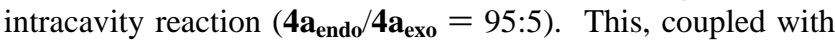

(25) The mechanism of guest-exchange has not yet been established. It may even involve local dissolution of the host followed by its recrystallization. For related work, see references $5 \mathrm{f}$ and $8 \mathrm{~b}$.

(26) The first-order expression of intracavity reaction is (mole of $\mathbf{2 a}$ consumed)/h $=k_{1}{ }^{\text {cav }}$ (mole of $\mathbf{2 a}$ included). If the intracavity reaction is rate-determining, the rate expression for the catalytic reaction would be $($ mole of $\mathbf{4 a}$ formed $) / \mathrm{h}=($ mole of $\mathbf{2} \mathbf{a}$ consumed $) / \mathrm{h}=n k_{1}{ }^{\text {cav }}$ (mole of host 1), where $n$ is the number of included guest molecules in the cavity. Under the conditions of catalytic reactions using a 1:20 (2a to 3 ) mixture, $n \cong 1$, as stated in the text. This indicates that $k^{\mathrm{cat}}=k_{1}{ }^{\mathrm{cav}}$. The experimental values are $k^{\text {cat }}=0.20 \mathrm{~h}^{-1}$ (for nonpulverized host) or $0.33 \mathrm{~h}^{-1}$ (for pulverized host) and $k_{1}^{\text {cav }}=0.3 \mathrm{~h}^{-1}$. 
the competitive inhibition effects of methyl benzoate, is also in a strong support of the cavity mechanism.

\section{Concluding Remarks}

The internal cavities of host $\mathbf{1}$ play essential roles in the present systems. (1) The two reactant molecules of different polarity characters are assembled in the same cavity. ${ }^{27}$ (2) The preorganized intracavity reactions exhibit remarkable rate enhancements as well as high stereoselectivities. (3) The products either leave the cavities or stay therein, resulting in turnover or deactivation of the catalyst. These are also what are characteristic of zeolitic ${ }^{4}$ as well as enzymatic catalyses. ${ }^{28}$

The present work thus suggests a potential utility of this type of microporous crystals as functional organic analogs of zeolites and also as a new type of enzyme mimics, where a decisive factor is how product inhibition is minimized. ${ }^{29}$ In addition to the specific points pertaining to the present systems, there are a number of general concerns. One is the types of reactions. In principle, product/reactant exchange would be facilitated when the products have lower hydrogen-bonding abilities than the reactants for either steric or electronic reasons. An extreme case would be such reactions as decarboxylation, where the hydrogen-bonding sites are lost upon reaction. Another is molecularity. Associative bimolecular reactions including the present Diels-Alder reactions yield one molecule of product, whose liberation at the sacrifice of fixing two reactant molecules upon product/reactant exchange in the cavity must be entropically very unfavorable. Dissociative unimolecular reactions yielding two or more product molecules would be much more favorable in this respect. A third point of interest is a particular use of water as a solvent of the liquid phase. Water may weaken host-guest hydrogen-bonding and hence give rise to a higher degree of reversibility in the host-guest complexation. This may also facilitate product/reactant exchange. ${ }^{30}$

\section{Experimental Section}

General Procedures. Compound 1, prepared as before, ${ }^{2}$ was recrystallized from a mixture of ethyl acetate and benzene. ${ }^{9}$ Single crystals (approximate size, $1 \times 1 \times 1 \mathrm{~mm}^{3}$ ) of adduct $\mathbf{1} \cdot 2\left(\mathrm{CH}_{3} \mathrm{CO}_{2^{-}}\right.$ $\left.\mathrm{CH}_{2} \mathrm{CH}_{3}\right) \cdot 2\left(\mathrm{C}_{6} \mathrm{H}_{6}\right)$ obtained were heated at $200{ }^{\circ} \mathrm{C}$ in vacuo for $10 \mathrm{~h}$ to give pieces of apohost $\mathbf{1}$, which apparently retained the shape and size of the original single crystals. Pulverization of the apohost was effected by using a mortar and a pestle.

Catalytic reactions were carried out under nitrogen at $25^{\circ} \mathrm{C}$ by using a 1:20 mixture of dienophile $\mathbf{2 a}$ or $\mathbf{2 b}(1.5 \mathrm{mmol})$ and diene $\mathbf{3}$ (30 $\mathrm{mmol})$ in the absence and presence of the apohost as either nonpul-

(27) For examples of templated bimolecular or multimolecular reactions, see: (a) Diederich, F.; Lutter, H.-D. J. Am. Chem. Soc. 1989, 111, 84388446. (b) Anderson, S.; Anderson, H.-L.; Sanders, J. K. M. Acc. Chem. Res. 1993, 26, 469-475. (c) Kelly, T. R.; Bridger, G. J.; Zhao, C. J. Am. Chem. Soc. 1990, 112, 8024-8034. (d) Nowick, J. S.; Feng, O.; Tjirijua, P.; Ballester, P.; Rebek, J., Jr. Ibid. 1991, 113, 8831-8839.

(28) For the enzymes catalyzing the Diels-Alder reactions, see: Oikawa, H.; Katayama, K.; Suzuki, Y.; Ichihara, A. J. Chem. Soc., Chem. Commun. 1995, 1321-1322. For the catalytic antibodies for the Diels-Alder reactions, see: (a) Hilvert, D.; Hill, K. W.; Nared, K. D.; Auditon, M.-J. M. J. Am. Chem. Soc. 1989, 111, 9261-9262. (b) Braisted, A. C.; Schultz, P. G. Ibid. 1990, 112, 7430-7431.

(29) Cf., Mackay, L. G.; Wylie, R. S.; Sanders, J. K. M. J. Am. Chem. Soc. 1994, 116, 3141-3142.

(30) When dipped in an aqueous solution of an appropriate guest such as cyclohexanol, cyclohexanediol, and alkyl acetate, apohost 1 binds two molecules of the guest together with 3-5 molecules of water (Aoyama, Y.; Imai, Y.; Endo, K.; Kobayashi, K. Tetrahedron 1995, 51, 343-352). The guest-binding turns out to be reversible. For example, exchange between ethyl acetate and propyl acetate readily takes place when the ethyl acetate adduct is dipped in an aqueous solution of propyl acetate (Aoyama, Y.; Oue, Y.; Sawaki, T.; Endo, K. unpublished results). verized pieces prepared as above or pulverized powders. The reactions were monitored by occasional sampling and analysis $\left({ }^{1} \mathrm{H}\right.$ NMR and/or gas chromatography) of the liquid phase. The reproducibility of the rate constants is within 7 or $10 \%$ for runs with pulverized or nonpulverized host, respectively.

Solid-state guest-binding and guest-exchange studies were carried in a similar manner as reported for related systems. ${ }^{8 a, b}$ Pieces of reactant adduct $\mathbf{1} \cdot 2(\mathbf{2 a}) \cdot 2(\mathbf{3})$ or $\mathbf{1} \cdot 2(\mathbf{2} \mathbf{b}) \cdot \mathbf{3}$ were placed in the vapor phase of a liquid mixture of the reactants, or directly in the liquid phase for adduct $\mathbf{1} \cdot 2(\mathbf{2 b}) \cdot \mathbf{3}$, in a sealed tube at $25^{\circ} \mathrm{C}$. A few pieces were picked up at appropriate time intervals, dissolved in DMSO- $d_{6}$, and analyzed by ${ }^{1} \mathrm{H}$ NMR for the progress of the intracavity reactions.

Host 1 could be recrystallized either (a) by allowing the vapor of diene $\mathbf{3}$ to slowly diffuse into a solution of $\mathbf{1}$ in dienophile $\mathbf{2 a}$ or $\mathbf{2 b}$ at room temperature or (b) by cooling a solution of $\mathbf{1}$ in a dienophilediene mixture at $-23{ }^{\circ} \mathrm{C}$. Single crystals free from Diels-Alder products were obtained only for the acrylate-diene $(\mathbf{2 b}-\mathbf{3})$ system in method $b$.

X-ray Structure Determination. A crystal of $\mathbf{1} \cdot 2(\mathbf{2 b}) \cdot \mathbf{3}$ with dimensions of $0.2 \times 0.3 \times 0.35 \mathrm{~mm}$ was mounted in a sealed capillary. Diffraction data were collected on a Rigaku RAXIS II imaging plate area detector using graphite-monochromated Mo $\mathrm{K} \alpha$ radiation $(\lambda=$ $0.71073 \AA$ ) at $230 \mathrm{~K}$. The accurate unit cell parameters used for refinement were determined by least-squares calculations on the setting angles for 25 reflections with $2 \theta=20-25^{\circ}$ that were collected on an Enraf Nonius CAD4 diffractometer using the same radiation under the same conditions. Reflection data were corrected for both Lorenz and polarization effects. The linear absorption coefficient $\mu$ for Mo K $\alpha$ radiation is $0.76 \mathrm{~cm}^{-1}$, and absorption correction was not applied.

The structure was solved by a combination of the direct method using SIR92 program and the Fourier techniques using DIRDIF92 program. All of the non-hydrogen atoms were refined anisotropically by full-matrix least-squares calculations. Some hydrogen atoms were located from difference Fourier maps and refined isotropically. The rest, except for one hydrogen atom on each methylene carbon of cyclohexadiene, were introduced at calculated positions and fixed. Each refinement was continued until all shifts were smaller than one-third of the standard deviations of the parameters involved. The weighting scheme $w^{-1}=\left(\sigma^{2}\left(F_{\mathrm{o}}\right)+\left(0.0015 F_{\mathrm{o}}\right)^{2}\right)$ was employed for the crystal. The final difference Fourier maps did not show any significant features. These calculations were performed on an INDY workstation by using the teXsan crystallographic software package of Molecular Structure Corporation. The crystal structure was visualized by using the Cerius 2 set of computer programs of Molecular Simulations Incorporated, which were also used for determining the bond lengths, bond angles, dihedral angles, and many other intermolecular distances. The location of the double bonds in cyclohexadiene incorporated in column c was based on the bond lengths, bond angles, and dihedral angles thus determined. On the other hand, cyclohexadiene in column $\mathrm{c}^{\prime}$ looked like benzene, probably due to disorder; it was not possible to fix its orientation.

Acknowledgment. This work was supported by grant-inaids from the Ministry of Education, Science, and Culture, Japan, including that for COE Research "Design and Control of Advanced Molecular Assembly Systems" (no. 08CE2005) and also by CREST (Core Research for Evolutional Science and Technology) of Japan Science and Technology Corporation.

Supporting Information Available: Crystal parameters, tables of crystal structural data with thermal ellipsoid figure including atomic coordinates, $B_{\text {iso }} / B_{\text {eq }}$, anisotropic displacement parameters, bond lengths, bond angles, torsion angles, and non-

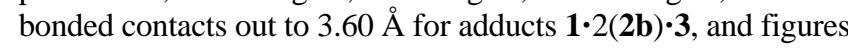
showing the time courses of the reactions in the absence and presence of methyl benzoate as an inhibitor (21 pages). See any current masthead page for ordering and Internet access instructions.

JA964198S 